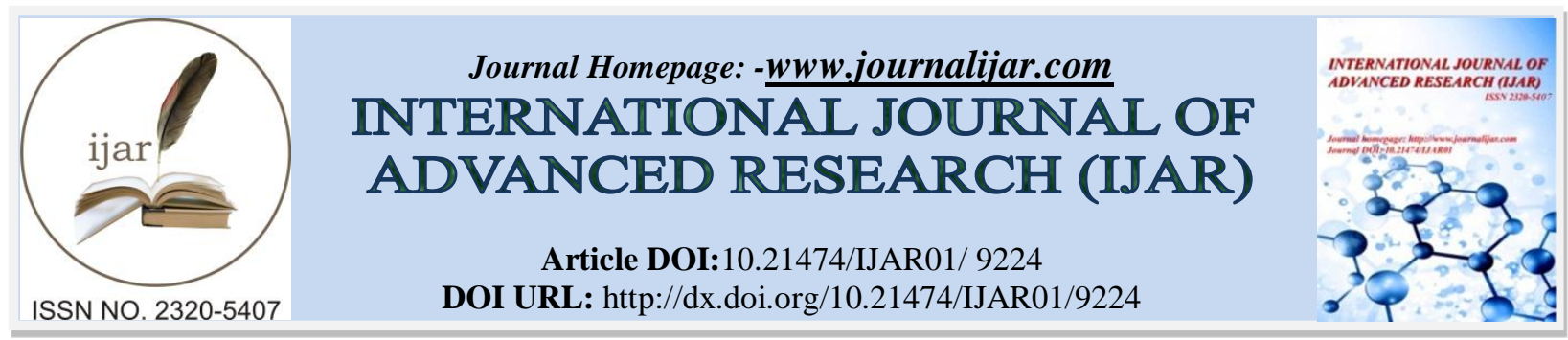

RESEARCH ARTICLE

\title{
NONTHROMBOTIC PULMONARY EMBOLISM BY FOREIGN BODY.
}

El Haddaji S, FENNICH H, SAIDI S, El Mesnaoui A and Bensaid Y.

Cardiovascular surgery department, university hospital IBN sina, Rabat.

\section{Manuscript Info}

………………...

Manuscript History

Received: 06 April 2019

Final Accepted: 08 May 2019

Published: June 2019

\section{Abstract}

Non-cruoric pulmonary embolisms are exceptional, their incidence is estimated at 5\% of all pulmonary embolisms, they can be septic, gaseous, fatty, metastatic, amniotic, or foreign body. We report the case of a 55-year-old patient who had been mastectomized, and who received adjuvant chemotherapy through The implantable catheter chamber implanted at the left subclavian venous. the patient presented in a table of left heart failure, and for whom the investigations concluded of a migration of an implantation chamber catheter responsible for non-cruoric pulmonary embolism and endovascular ablation was successfully performed.

Rupture of catheters with pulmonary embolization by distal fragments is a rare complication of implantable catheter chamber. Its incidence with or without embolism varies between 0.9 and $1.7 \%$. Several factors contribute to the occurrence of a rupture of the catheter namely the use of inappropriate material, the traumatic section during the insertion or the extraction of the catheter, the untimely maneuvers and the forced rinsing of the rooms by small syringes (especially if the catheter is weakened and in the pre-rupture stage), the torsion of the catheter close to its anastomosis with the housing (which is causing more proximal rupture), as well as the erroneous positioning, the prolonged use and wear of the catheter. The malposition, the thrombosis, the fibrin sleeves are the main complications that can mimic this clinical picture. In this case, radiological investigations, chest $\mathrm{x}$-ray and ultrasound, provide valuable information to confirm or refute a particular diagnosis.

Pulmonary embolization by the distal end of a disrupted catheter is a rare complcation that can have lethal consequences. Given the suspicion of a pulmonary embolism, the non-cruelty even exceptional cause is likely, the diagnosis must be evoked for proper management

Copy Right, IJAR, 2019,. All rights reserved.

\section{Introduction:-}

Non-cruoric pulmonary embolisms are exceptional, their incidence is estimated at $5 \%$ of all pulmonary embolisms, they can be septic, gaseous, fatty, metastatic, amniotic, or foreign body (1). The implantable catheter chamber (ICC) plays an important role in the therapeutic management of cancer patients, providing them a long-term venous access. However, its establishment and its use are not without risks with the possibility of sporadic occurrence of catheter rupture and the migration of the distal fragment in the pulmonary arteries. 


\section{Case report:}

We report the case of a 55-year-old patient who had been mastectomized seven years ago for the right breast and who received adjuvant chemotherapy through a ICC implanted at the left subclavian venous (VSC), followed by radiotherapy, in remission, presenting acute dyspnea (stage III NYHA) with palpitation.

The clinical examination and the ECG are without abnormality, the standard chest X-ray shows a normal-looking cardiac figure, as well as the pulmonary parenchyma, with presence of a catheter on the air of the left pulmonary artery; at ETT, Right ventricle is slightly dilated, with good systolic function, with moderate pulmonary hypertension, left ventricle is of normal size and contractility. A migration of an implantation chamber catheter responsible for non-cruoric pulmonary embolism was concluded and endovascular ablation was successfully performed.

\section{Discussion:-}

Rupture of catheters with pulmonary embolization by distal fragments is a rare complication of ICC. Its incidence with or without embolism varies between 0.9 and $1.7 \%$ (2). Several factors contribute to the occurrence of a rupture of the catheter namely the use of inappropriate material, the traumatic section during the insertion or the extraction of the catheter, the untimely maneuvers and the forced rinsing of the rooms by small syringes (especially if the catheter is weakened and in the pre-rupture stage), the torsion of the catheter close to its anastomosis with the housing (which is causing more proximal rupture), as well as the erroneous positioning, the prolonged use and wear of the catheter $(2,3)$. The malposition, the thrombosis, the fibrin sleeves are the main complications that can mimic this clinical picture. In this case, radiological investigations, in this case chest $\mathrm{x}$-ray and ultrasound, provide valuable information to confirm or refute a particular diagnosis.

Repeated shoulder and arm movements may be responsible for friction and friction of the catheter against the bone and therefore compromise the operation of the catheter and create a zone of weakness that will eventually give way with a section of the catheter (4). The distal fragment is likely to migrate to the cardiac cavities, in this case the right atrium, before moving in some cases to the pulmonary arteries, or to come to lodge exceptionally in the coronary sinus. The consequences of this migration may be daunting and may result in myocardial perforation or necrosis resulting in cardiac tamponade, myocardial infarction, valvular perforation, cardiac arrhythmia with the ultimate possibility of cardiac arrest (5). These foreign bodies are thrombogenic and run the risk of fibrinocruoric pulmonary embolism. Sometimes they are the site of microbial growth and therefore give rise to endocarditis, thrombus superinfections, mycotic aneurysms and pulmonary abscesses.

\section{Conclusion:-}

Pulmonary embolization by the distal end of a disrupted catheter appears to be a specific complication of catheter chambers implanted at the subclavian vein. This rare complication can have lethal consequences. It settles late after catheter chambers insertion and is usually asymptomatic. Given the suspicion of a pulmonary embolism, the noncruelty even exceptional cause is likely, the diagnosis must be evoked for proper management

\section{References: -}

1. Derick Asah, DO; Shine Raju, MD; Subha Ghosh, MD; Sanjay Mukhopadhyay, MD; and Atul C. Mehta, MD, FCCP. Nonthrombotic Pulmonary Embolism From Inorganic Particulate Matter and Foreign. CHEST 2018 (Article in press)

2. BodiesSurov A, Wienke A, Carter JM, et al. Intravascular embolization of venous catheter-causes, clinical signs, and management: a systematic review. JPEN J Parenter Enteral Nutr. 2009;33(6): 677-685.

3. Onal B, Coskun B, Karabulut R, Ilgit ET, Turkyilmaz Z, Sonmez K. Interventional radiological retrieval of embolized vascular access device fragments. Diagn Interv Radiol. 2012;18(1):87-91.

4. Bhatt VR, Gupta S, Lowry J, Dhar M. Port-a-cath embolisation to pulmonary artery. BMJ Case Reports. 2011;2011.

5. Jackson BS, Sepula M, Marx JT, Cannon CM. Inferior vena cava filter limb fracture with embolization to the right ventricle. J Emerg Med. 53(2):248-251. 